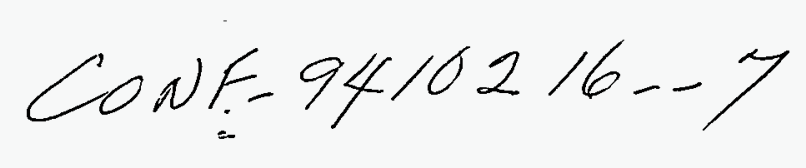

\title{
IMPROVING THE ACTION REQUIREMENTS OF TECHNICAL SPECIFICATIONS: A RISK-COMPARISON OF CONTINUED OPERATION AND PLANT SHUTDOWN*
}

\author{
I.S. Kim, T. Mankamo** and P.K. Samanta \\ Department of Advanced Technology \\ Brookhaven National Laboratory \\ Upton, New York 11973 \\ **Avaplan Oy, Finland
}

\begin{abstract}
When the systems needed to remove decay heat are inoperable or degraded, the risk of shutting down the plant may be comparable to, or even higher than, that of continuing power operation with the equipment inoperable while giving priority to repairs. This concern arises because the plant may not have sufficient capability for removing decay heat during the shutdown. However, Technical Specifications (TSs) often require "immediate" shutdown of the plant. In this paper, we present risk-based analyses ${ }^{1}$ of the various operational policy alternatives available in such situations, with an example application to the standby service water (SSW) system of a BWR. These analyses can be used to define risk-effective requirements for those standby safety systems under discussion.
\end{abstract}

\section{Introduction}

\subsection{Current Requirements and Definition of the Problem}

Limiting conditions for operation (LCOs) define the allowed outage times (AOTs) and the actions to be taken if the repair cannot be completed within the AOT. Typically, the action required is plant shutdown. However, in situations where the risk associated with the action, i.e., the risk of plant shutdown given a failure in the safety system, may be substantial, a strategy is needed to control the risk implications. When a system needed to remove decay heat is inoperable or degraded at power, shutting down the plant may not necessarily reduce risk, compared to continuing power operation and giving priority to completing the repairs. Analyzing these TS requirements and exploring various available alternatives is the focus of this paper.

For example, for a residual heat removal (RHR) system of a BWR plant in the United States consisting of three trains, a 3-day AOT is defined for single-train failures. However, the action statement requires that the plant is shut down when failures are detected in multiple (i.e., two or three) trains.

These action requirements primarily are directed towards minimizing the risk during power operation, assuming that shutting down the plant is relatively safe; namely, the risk of shutdown is

"This work was performed under the auspices of the U.S. Nuclear Regulatory Commission.

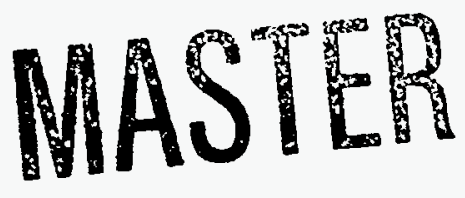


assumed to be negligible. This is not necessarily a reasonable assumption for such a system that removes decay heat. A comparative analysis of risk impacts of action alternatives can address these failure situations.

\subsection{Failures in Systems for Removing Decay Heat} be impaired:

When failures occur in the following systems, the ability of the plant to remove decay heat may

1) RHR system of a BWR or PWR that provides long-term removal of decay heat

2) Auxiliary feedwater (AFW) system of a PWR which provides feedwater to steam generators to remove decay heat from the primary system

3) Component cooling water (CCW) system of a PWR that provides cooling water to the RHR system

4) Standby service water (SSW) system of a BWR or PWR that subsequently removes heat from the RHR or CCW system for the BWR or PWR, respectively

5) Emergency power system of a BWR or PWR that provides electric power to the systems used to remove decay heat following a reactor scram

Shutting down the plant in such failures may impose substantial risk, which may be comparable or exceed the risk associated with continuing power operation and giving priority to the repairs. Hence, in evaluating the AOTs or action statements for these systems, the shutdown risk can be taken into account explicitly and compared with the risk of continued power operation.

\section{Basic Concepts of the Comparative Analysis of LCO Risks}

\subsection{Comparison of Conditional LCO Operating and Shutdown Risks}

When a safety system enters an LCO because of failure of one or more components in the system, TSs allow for one of the two alternatives: a) continue power operation and repair the failed equipment within the defined AOT, or b) shut down the plant to complete the repairs in a shutdown state. We call these alternatives the basic operational alternatives, and the risks associated with these alternatives the LCO risks. The risk associated with repairing the equipment while continuing power operation is called LCO operating risk; the risk associated with shutting the plant down is called LCO shutdown risk.

Figure 1 shows a conceptual plot of LCO operating and shutdown risks in terms of core-damage frequency for failure of a system which is needed to remove decay heat. At time A when the failure is detected, the two basic operational alternatives are applicable, i.e., continued power operation, and plant shutdown. The solid line represents the risk profile for continued operation, while the dotted line is the profile for the shutdown.

Upon detecting the failure at time A, the LCO operating risk increases above the baseline due to the increased unavailability of the initially affected (i.e., failed or degraded) system during potential 


\section{DISCLAIMER}

Portions of this document may be illegible in electronic image products. Images are produced from the best available original document. 
occurrences of accident scenarios requiring it to be operational to prevent core damage. The baseline represents the level of risk associated with power operation when no known failures exist.

The initial increase in the LCO shutdown risk (Figure 1) results from the system's unavailability during the potential occurrences of accident scenarios initiated by events occurring while the plant is being brought to shutdown. Specifically, the increase in risk in the initial stage of shutdown arises from: 1) the unreliability of the systems which are needed during the change in plant's state, or which must be started up, and 2) the vulnerability of the plant to transients caused by the changes in the plant's state. After entering a stable shutdown state, the risk level usually decreases with time because of the diminishing decay heat, meaning lower capacity requirements on safety systems, and longer time available for recovery if a critical safety function is lost during a shutdown-cooling mission. Obtaining a lower risk level in a stable shutdown mode, compared to the continued-operation alternative, is the principal motivation of going to shutdown.

At time B, when the component is repaired and returned to service, both operating and shutdown risks decrease. The operating risk decreases to the baseline risk level, i.e., the level before the failure was detected, whereas the shutdown risk decreases below the baseline risk level for the power operational mode, because of the much lower rate of heat production in the reactor during shutdown compared to power operation. Another small peak in the shutdown risk at time $\mathrm{C}$ arises from the unavailabilities of systems that are needed when the plant is restarted up, and the plant's vulnerability to transients that may be caused by the changes in the operational mode. In this period, the risk is also a function of the rate of heat production, as represented by a small dip which then slowly increases to the baseline risk level as the plant reaches full power operation.

The period that is directly relevant to evaluating action requirements or AOTs for failures in the safety systems is from time A to time B, i.e., the predicted or actual repair time for the component. The risk over this period, i.e., core-damage probability, can be obtained by integrating the conditional CDF to compare the LCO operating and shutdown risks. If the operating risk is smaller than the shutdown risk, then, from a risk point of view, the alternative of continued operation is preferable to the shutdown alternative, and vice versa.

\subsection{Comparison of LCO Operating and Shutdown Risks}

Figure 2 compares the core-damage probability (CDP) contributions over the repair time, beginning from time $A$ when the failure is detected. The CDP for operating risk is smaller than that for shutdown risk until time $\mathrm{X}$, when the two curves intersect. Therefore, from a risk perspective, it is more beneficial to continue power operation than to shut down the plant if the operability of the initially affected system can be restored before time $\mathrm{X}$. Where the repair takes longer than the period A to X, it is advisable to shut down the plant.

\section{DISCLAIMER}

\footnotetext{
This report was prepared as an account of work sponsored by an agency of the United States Government. Neither the United States Government nor any agency thereof, nor any of their employees, makes any warranty, express or implied, or assumes any legal liability or responsibility for the accuracy, completeness, or usefulness of any information, apparatus, product, or process disclosed, or represents that its use would not infringe privately owned rights. Reference herein to any specific commercial product, process, or service by trade name, trademark, manufacturer, or otherwise does not necessarily constitute or imply its endorsement, recommendation, or favoring by the United States Government or any agency thereof. The views and opinions of authors expressed herein do not necessarily state or reflect those of the United States Government or any agency thereof.
} 


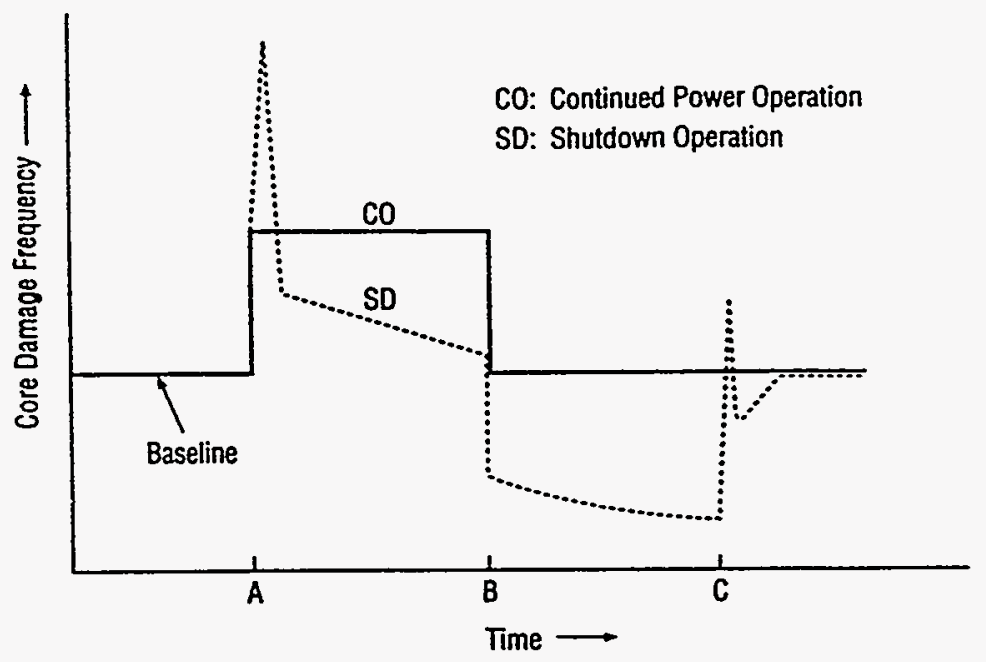

Figure 1 Comparison of LCO risks (core-damage frequency) for the basic operational alternatives of continued power operation and shutdown

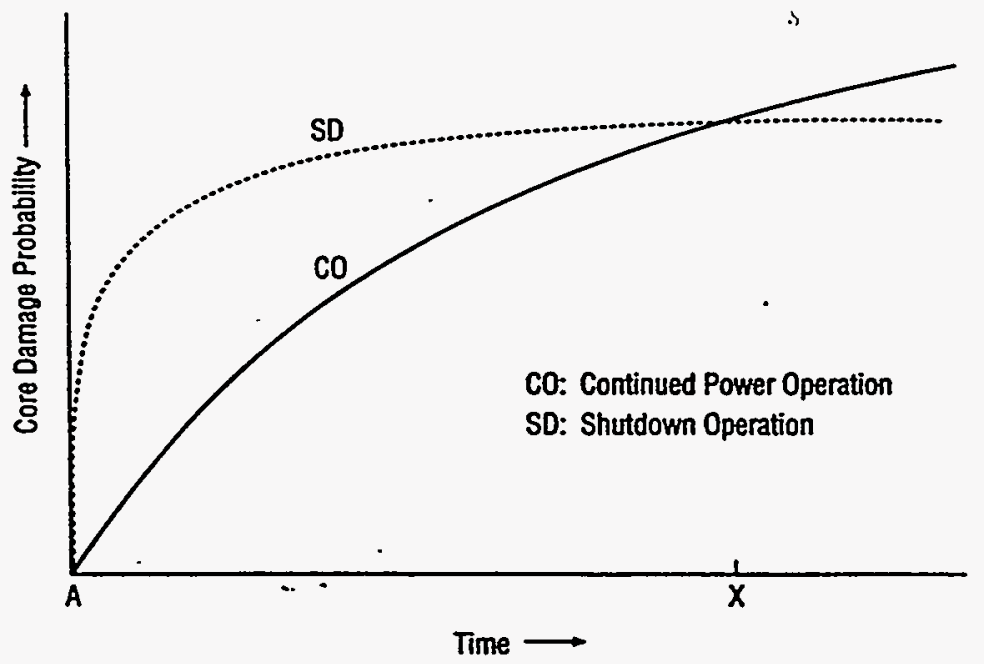

Figure 2 Comparison of LCO risks (core-damage probability) for the basic operational alternatives of continued power operation and shutdown 


\subsection{Other Considerations in Defining Action Requirements}

The risk profiles discussed above are based on several assumptions. An important assumption was that, in the case of the shutdown alternative, the plant is shut down directly after the failure is detected. However, in general, some AOT may be useful so that plant personnel can evaluate the repairs needed and restore the operability of the failed equipment without shutting down the plant, at least for short repairs.

Suppose that 3 days of AOT is given for a failure situation in the technical specifications and that the plant personnel cannot repair the component within the AOT. They may shut down the plant three days after finding the failure. In this case, the failure will incur LCO operating risk from the time the failure was detected until the shutdown is initiated, and also LCO shutdown risk. Compared to a plant shutdown right after the failure detection, this case will incur a larger risk by the risk accumulated before the plant is actually shut down. Hence, the timing of shutdown should be considered in determining riskeffective action requirements that will minimize the total risk impact associated with a given failure.

Furthermore, oftentimes we do not know exactly how long the repair of certain failures will take. The distribution of repair time should be considered in assessing the risk associated with the failures. In addition to the timing of shutdown and the repair time, other issues should be taken into account in determining risk-effective action requirements, e.g., whether the status of redundant train(s) should be checked, and whether the plant should go to hot shutdown or cold shutdown as the optimum target state. These issues can be addressed by sensitivity analyses.

\section{Example Application to Standby Service Water System}

The method for evaluating LCO operating and shutdown risks, called risk-comparison approach, was applied to the standby service water (SSW) system of a BWR. The event sequences were modeled using shutdown transient diagrams and extended event sequence diagrams, particularly focussing on the transients that may occur during the transition to shutdown.

In this section, we present the results of quantifying the LCO operating and shutdown risks for failures in the SSW system, after briefly introducing the system and the present action requirements. We then summarize the practical insights from these analyses to control the risk implications of such failures. A detailed description of the sequence modeling and sensitivity analyses can be found in Reference 2 .

\subsection{Standby Service Water System and Present Action Requirements}

The SSW system, consisting of three subsystems, A, B, and C, removes heat from plant equipment that require cooling water for a safe reactor shutdown. SSW pumps A and B each has a 12,000 gpm capacity, while SSW pump C, dedicated to the high pressure core spray (HPCS) system, has a much smaller $(1,300 \mathrm{gpm})$ capacity.

The SSW subsystems, especially A and B, provide cooling water to many safety-significant components, such as the heat exchangers of the RHR system, room/pump coolers for the low-pressure core-spray (LPCS) and reactor-core-isolation cooling (RCIC) systems, and jacket coolers of diesel generators. Hence, a failure or degradation in the SSW system will affect the operability of other systems 
which are supported by the SSW system. For example, the failure of SSW subsystem A also will cause RHR subsystem $A$ and DG subsystem $A$ to be inoperable along with front-line systems, LPCS and RCIC.

Table 1 summarizes the action requirements for the SSW system which are applicable to the power operation mode. For a single failure, i.e., when SSW subsystem A, B, or C is inoperable, the TS allows 3 days; if the operability of the failed subsystem cannot be restored within 3 days, then the plant must be shut down.

Table 1 Action Requirements for the SSW System

\begin{tabular}{ll}
\hline \hline \multicolumn{1}{c}{ Inoperable SSW Subsystems } & AOT \\
\hline \hline$A$ or $B$ or $C$ & 3 days \\
"A and C" or "B and C" & 3 days \\
$A$ and $B^{a}$ & 0 hours \\
$A, B$, and $C^{a}$ & 0 hours \\
\hline \hline
\end{tabular}

aWhenever both SSW subsystems (A and B) are inoperable, if cold shutdown cannot be attained as required by this action, the reactor's coolant temperature should be kept as low as practical by using aiternate methods of heat removal.

For double failures of the SSW system, the TS gives different AOTs, depending on which subsystems are inoperable. When SSW trains $A$ and $C$, or $B$ and $C$ are down, the plant may continue power operation with the equipment inoperable up to 3 days; namely, these double failures have the same AOT as the single failures.

When SSW subsystems A and B, or all SSW subsystems (triple failures) are inoperable, the TS requires "immediate" plant shutdown ( 0 hours of AOT). Then, the TS also limits the timing of shutdown so that the plant at least should be in hot shutdown within the next 12 hours, and in cold shutdown within the following 24 hours.

\subsection{Risk Comparison of the Basic Operational Alternatives}

Table 2 gives the LCO operating and shutdown risks for failures in the SSW system. Figures 3 and 4 show how the conditional core-damage frequency and core-damage probability change for the continued power operation (CO) and shutdown (SD) alternatives in single, double, and triple failures of the SSW system. 
Table 2 Risk Quantification for Failures in the SSW System

\begin{tabular}{lccc}
\hline $\begin{array}{c}\text { LCO State } \\
\text { (Failures of } \\
\text { SSW Trains) }\end{array}$ & $\begin{array}{c}\text { Core-Damage } \\
\text { Frequency in Power } \\
\text { Operation State } \\
\text { (per year) }\end{array}$ & $\begin{array}{c}\text { CDF Increase } \\
\text { Factor }\end{array}$ & $\begin{array}{c}\text { Crossing Point of the } \\
\text { SD/CO Alternatives } \\
\text { (days) }\end{array}$ \\
\hline Baseline & $2.1 \mathrm{E}-6$ & 1.0 & N/A \\
Single (A) & $1.5 \mathrm{E}-5$ & 7.4 & $\sim 3$ \\
Double (AB) & $3.3 \mathrm{E}-4$ & 160 & $\sim 3$ \\
Triple (ABC) & $7.4 \mathrm{E}-3$ & 3600 & $\sim 14$ \\
\hline \hline
\end{tabular}

\begin{tabular}{c|c|c}
\hline \multicolumn{3}{c}{$\begin{array}{c}\text { Core-Damage Probability } \\
\text { per Failure Situation }\end{array}$} \\
\hline $\begin{array}{c}\text { Continued } \\
\text { Operation } \\
\text { (CO) }\end{array}$ & $\begin{array}{c}\text { Controlled } \\
\text { Shutdown } \\
\text { (SD) }\end{array}$ & $\begin{array}{c}\text { CDP Ratio } \\
\text { (SD/CO) }\end{array}$ \\
\hline \hline N/A & N/A & N/A \\
$2.3 \mathrm{E}-8$ & $5.7 \mathrm{E}-8$ & 2.5 \\
$4.5 \mathrm{E}-7$ & $9.6 \mathrm{E}-7$ & 2.1 \\
$1.1 \mathrm{E}-5$ & $3.3 \mathrm{E}-5$ & 3.0 \\
\hline \hline
\end{tabular}




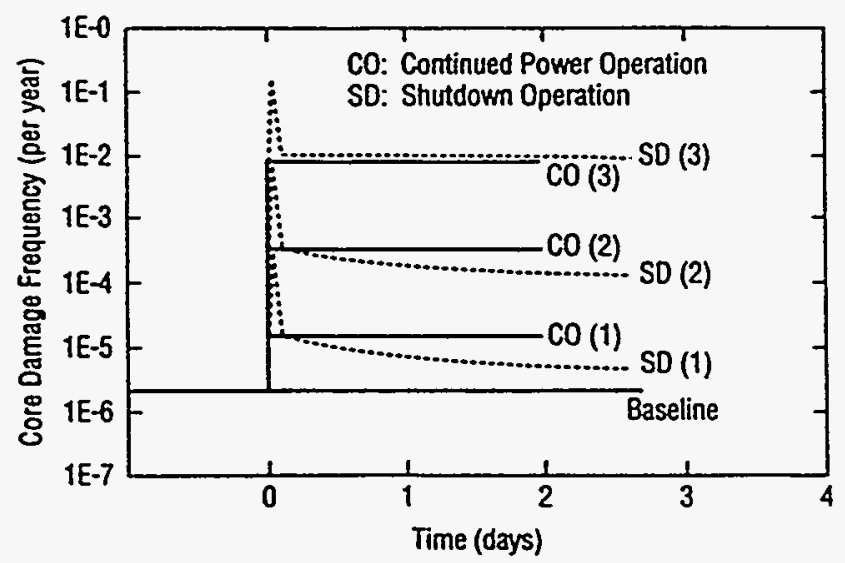

Figure 3 Conditional core-damage frequency for the continued operation and shutdown alternatives in failures of the SSW system (For example, $\mathrm{CO}(2)$ denotes the $\mathrm{CO}$ alternative for double-train failures)

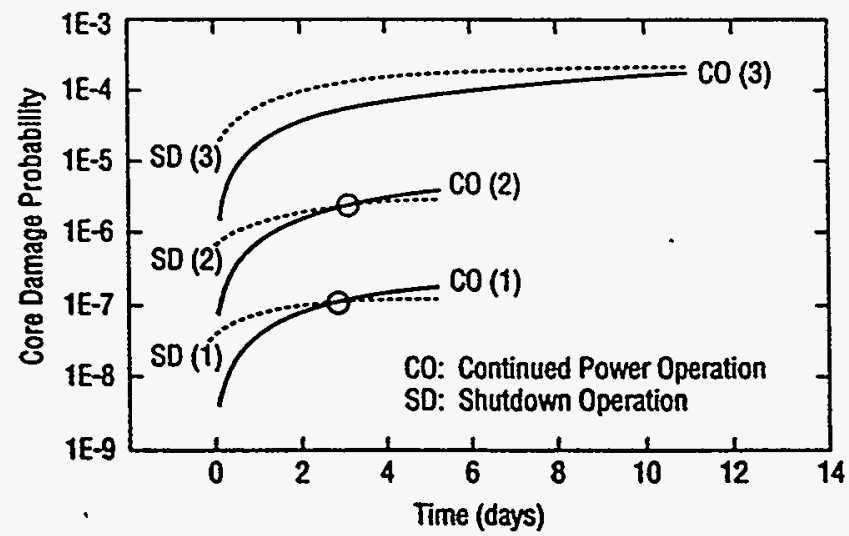

Figure 4 Cumulative core-damage probability over predicted repair time in failures of the SSW system (For example, SD(2) denotes the SD alternative for double-train failures) 
1. Single-Failure Situation: Where one SSW train (e.g., train A) is detected failed during power operation, the core-damage frequency increases by a factor of about 7 over the baseline (see, Table 2). If the $\mathrm{CO}$ alternative is taken, the core-damage frequency will remain at this level until the operability of the failed train is restored. If the SD alternative is taken (directly after detecting the failure), then the plant temporarily will have higher CDF than the operating CDF during the initial transition period of power reduction and state changes. However, after this initial increase, the CDF slowly declines, resulting in a smaller and smaller CDF compared to the operating CDF. The estimate of CDP over time indicates that the risk of continued operation is smaller than that for shutdown until about 3 days (see, Figure 4).

2. Double-Failure Situation: When two SSW trains (e.g., trains A and B) are detected failed, the CDF profiles for both $C O$ and SD alternatives are similar to those in a single failure, except that the CDF is increased by a factor of 160 over the baseline. Figure 4 shows that the CDPs for CO and $S D$ aiternatives again intersect at about 3 days.

3. Triple-Failure Situation: Where all the three SSW trains are detected failed, the conditional CDF dramatically increases by a factor of about 3600 over the baseline. However, in contrast to single-and double-failures, for several days $\mathrm{CDF}$ remains higher than for the $\mathrm{CO}$ alternative. The intersection of the CDPs occurs about 14 days after shutdown.

Figure 3 compares the SD risk profile for triple failures, with those for single and double failures. When all SSW trains are inoperable, the plant becomes vulnerable to loss of offsite power and loss of instrument air system initiating events, during shutdown as well as during power operation because of the resulting loss of the power conversion system and lack of major means to remove decay heat. In addition, these initiators have a higher frequency in shutdown states than in power operation state. As a consequence, the CDF remains high in the cold shutdown state, and the CDPs for the two alternatives cross at a long predicted repair time, i.e., 14 days (Figure 4).

Table 2 summarizes the results of this case study for failures in the SSW system of the BWR. These results include: 1) the CDF in the power operation state, 2) the increase in CDF for the continuedoperation alternative, 3) the crossing point of the core-damage probabilities for the shutdown and continued power operation (SD/CO) alternatives, and 4) the expected core-damage probability for different failure situation in SD/CO alternatives along with the ratio between these probabilities. In particular, the ratio of the CDPs for SD/CO alternatives indicates that the SD alternative is unfavorable in all three failures of the SSW system.

\subsection{LCO Recommendations for the Specific Example Analyzed}

The risk-comparison analysis of failures in the SSW system of the particular plant resulted in the following recommendations:

1) The present AOT requirement for a single SSW-train failure is 3 days. This AOT may remain the same with the additional condition that, by the end of the first day, redundant trains are tested to assure that there are no additional failures. If the repair of the initial failure is completed within the first day, then no additional tests are required. If feasible, any diagnostic measure that can determine the condition of the redundant train(s), should 
precede, or replace the need for, an actual demand test, particularly when the test may have adverse effects. ${ }^{3}$

2) The SSW trains are tested relatively frequently during power operations because they are run for mixing chemical additives and to test other safety-system components. The recommendation to test redundant SSW train(s) should not result in unnecessary additional testing. This recommended test can be omitted if a successful test was performed recently, e.g., in the previous 72 hours, and if there is no clear indication of a common-cause failure.

3) The current LCOs distinguish among different double failures; for example, a 3-day AOT is given for failure of SSW trains A and C, and B and C, but shutdown is required for failure of SSW trains A and B. Similarly, shutdown is required for failure of all three SSW trains. This study recommends 2 days of AOT for double- and triple-failures in the SSW system. With this change, the AOT for all double failures in the SSW system will be the same. This recommendation is justified because the impacts on core-damage frequency of different double-failure combinations are similar.

In using this 2 days of AOT for double- and triple-failures in the SSW system, a decision needs to be made at the end of the first day whether one of the trains can be completely repaired by the end of the second day. If, by then, it is judged that this cannot be accomplished, then shutdown should be initiated immediately to avoid accumulating risk during power operation.

4) For multiple failures, if the repair time is expected to exceed 2 days, then shutdown should be initiated at the end of the first day, and cold shutdown should be reached within the next 12 hours. The time to reach cold shutdown differs from that currently allowed ( 12 hours to reach hot shutdown, and 24 hours to reach cold shutdown), because here, to minimize the risk impact, an orderly cold shutdown should be achieved without delay.

\section{General Recommendations for Risk-Based Action Statements}

The risk-comparison approach discussed thus far also was applied to the auxiliary feedwater system of a PWR. ${ }^{4}$ Figure 5 graphically represents the general recommendations drawn from these studies to improve the action statements from a risk perspective:

1) The use of an AOT may be defined in the following manner. The initial portion of the AOT can be used to complete short repairs. For longer repairs, the needed repair time is assessed within the first phase of the AOT. If it is considered longer than the AOT, then shutdown can be initiated to minimize the accumulation of risk during power operation with such a failure. To identify the situation more clearly, especially where common-cause failures are suspected, additional tests of redundant train(s) may be conducted. Then, the applicable AOT should be followed, depending on the outcome of the test. 
2) In the case of multiple failures, an AOT should be provided to allow at least one of the failed trains to be restored to operable status. As for a single failure, multiple failures also should have an AOT. This differs from some current TS requirements of immediate shutdown when multiple failures are detected. However, the AOT for multiple failures should be shorter than that for single failures.

3) Assessment of risk impact of staying in a particular mode (e.g., hot shutdown versus cold shutdown) can be used to decide on the applicable mode to be reached when a decision is made to shut down the plant. For example, in a BWR, the conditional CDF of staying in hot shutdown may be high compared to cold shutdown; if so, cold shutdown should be reached without delay.

4) If small risk is incurred, especially for continuing power operation, then the TS requirements can be relatively simple and flexible.

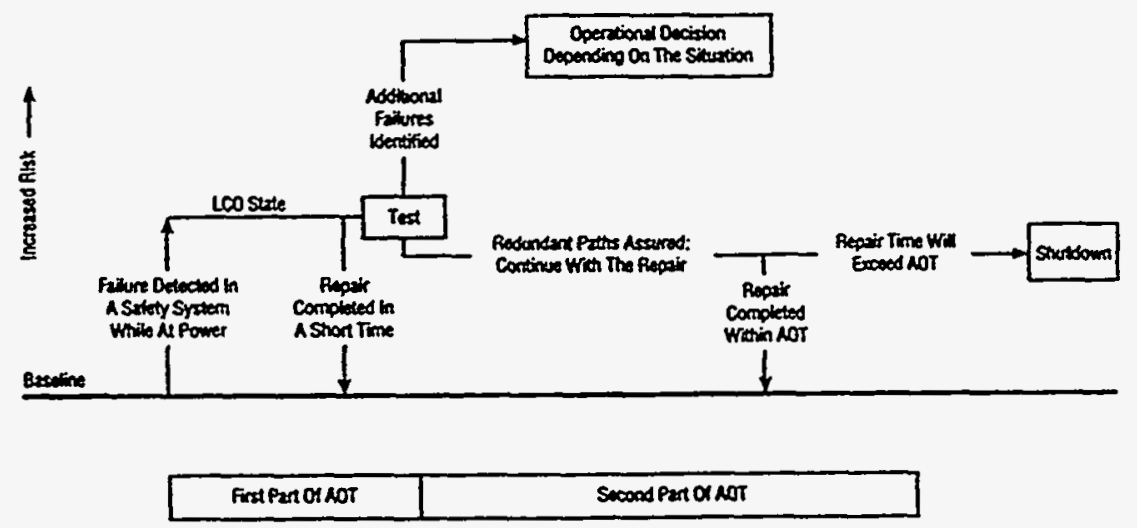

Figure 5 Recommendations for risk-based action requirements

There are several practical points that also should be taken into account in considering possible changes in the action requirements:

1) If an AOT is defined, it must be sufficiently long to complete a large percentage (e.g., $\sim 90 \%$ ) of repair needs; this will avoid any adverse effects of incomplete or hurried repairs.

2) The AOTs chosen should follow discrete values normally used in Technical Specifications such as 1 day, 2 days, 3 days, or 7 days, for ease of implementation.

3) Care should be taken that the relative risk-comparison of the operation alternatives is not the only factor in defining the action requirements. If mechanically followed, this approach could result in longer AOTs for multiple failures, thus possibly providing 
incentives to declare multiple failures when repairs for single failures cannot be completed within the prescribed AOT.

4) When AOTs for multiple failures are defined in TS, it implies that, when one failure is repaired, the action for the remaining fewer failures needs to be followed. There is a significant risk advantage to promptly repairing one of the failures in the case of multiple failures. In principle, AOTs should reflect this risk perspective, where possible, by consistently defining longer AOTs for fewer failures.

5) The requirement for additional testing of a redundant train should consider its adverse effects. If feasible, any diagnostic measure that can determine the condition of the redundant train should precede or replace the need for an actual demand test. In the special case where testing the redundant trains involves substantial adverse effects, ${ }^{3}$ then it may be more beneficial not to do so.

\section{REFERENCES}

1. P.K. Samanta, I.S. Kim, T. Mankamo and W.E. Vesely, Handbook of Methods for Risk-Based Analyses of Technical Specifications, NUREG/CR-6141, BNL-NUREG-52398 (in press).

2. T. Mankamo, I.S. Kim and P.K. Samanta, Technical Specification Action Statements Requiring Shutdown: A Risk Perspective with Application to the RHR/SSW Systems of a BWR, NUREG/CR5995, BNL-NUREG-52364, November 1993.

3. I.S. Kim, S. Martorell, W.E. Vesely and P.K. Samanta, Quantitative Evaluation of Surveillance Test Intervals Including Test-Caused Risks, NUREG/CR-5775, BNL-NUREG-52296, February 1992.

4. T. Mankamo, I.S. Kim and P.K. Samanta, Analyses of Action Requirements for Failures in the Auxiliary Feedwater System of a PWR, BNL Technical Report L-2289, August 1994. 